\title{
Scale Matters in Contextual Analysis of Extreme Right Voting and Political Attitudes
}

\author{
Quentin David, Jean-Benoit Pilet and Gilles Van Hamme*
}

\section{INTRODUCTION}

Extreme right voting is on the rise in numerous western countries, and attempts to understand the success of these parties have increased for more than fifteen years. Contextual factors, understood as the characteristics of the places in which individuals are embedded (David, Van Hamme, 2011; Agnew, 1996), have often been taken into consideration to explain their success (Coffe et al., 2007; Lubbers and Scheepers, 2000; Golder, 2003; Givens, 2002). Similarly, studies of citizens' attitudes towards immigrants and immigration have also integrated the importance of context (for an overview, see Ceobanu and Escandell, 2010). In both fields, the share of immigrants and the contextual economic conditions in the individual's environment have been identified as having the most significant impacts on political attitudes.

Most papers addressing the effect of contextual factors share a weakness: they define the context according to data availability and do not address the question of the appropriate scale to capture these effects. This paper is the first to test systematically the effect of two contextual factors (the presence of migrants and of unemployed workers) measured at various scales, on both extreme right voting and attitudes toward immigrants and immigration. The results clearly show that the estimated effects of the contexts, as well as their empirical significance, vary with the considered scales. The most significant impacts are found at intermediary scales, that is when the context is measured within circles of 5 to $12 \mathrm{~km}$ around one's residence or at the municipality scale. Our original database enabled us to perform these tests very systematically using two different

* Quentin David: LEM-CNRS (UMR 9221), Université de Lille, Sciences et Technologies, 59655 Villeneuve d'Ascq, France. quentin.david@univ-lille.fr Jean-Benoit Pilet: CEVIPOL, Université Libre de Bruxelles (ULB), Avenue FD Roosevelt 50, cp 124, B-1050 Brussels, Belgium. jpilet@ulb.ac.be. Gilles Van Hamme: IGEAT, Université Libre de Bruxelles (ULB), Avenue FD Roosevelt 50, cp 246, B-1050 Brussels, Belgium. gvhamme@ulb.ac.be. We would like to thank the two anonymous referees, David Stadelmann (the editor), Edoardo Di Porto, Etienne Farvaque, Abel François and various workshop participants for their helpful comments and suggestions. 
approaches: a concentric approach and a polarized approach. In the concentric approach, we compute the context of each individual at various distances $(0.5$, $1,2,3, \ldots, 30 \mathrm{~km}$ ) from her residence and test the effect of this context when measured at these different scales. Through the polarized approach, we consider three different fixed scales: the statistical district, the municipality, and the employment pool.

The impact of the environment on an individual's behaviour has long been studied in the social sciences. Electoral studies are not an exception in that respect. Early approaches of the so-called School of Columbia were based on local enquiries and insisted on the importance of social drivers in voting. These drivers included the area of residence (Berelson et al., 1954; Braconnier, 2010). However, though this interest in contexts never completely disappeared (at least in the US), psychological models of voting and rational choice theories of political behaviour have shifted their focus towards more individualistic approaches. These have left aside the relationship between individual voters and their environment, notably through the intensive use of national enquiries. In the early 2000 s, specialists of elections brought their contextual analyses back to the research agenda. In a special issue of Electoral Studies on the future of election studies, Franklin (2002) pointed to the integration of contextual variables as a promising way to move national election studies forward. The recent literature on voting behaviours confirms the usefulness of Franklin's claim.

While an increasing number of studies examine the impact of contextual factors, very few papers discuss the appropriate scale to assess these effects (Rink et al., 2009, constitutes a counterexample, as these researchers devote a few lines to explaining spatial expectations). The scales used for the contextual variables are most often selected on the basis of what is available. The paradox is that scholars recognise that it affects the results of empirical analysis (Dulmer and Klein, 2005; Arzheimer and Carter, 2009). We illustrate this point in this paper, showing that the use of different scales yields different conclusions regarding the impact of unemployment and immigration on extreme right voting and attitudes toward immigrants and immigration (ATII hereafter).

In contrast, geographers examine the choice of scale much more closely, but their studies have mostly produced results at the aggregate level and rarely replace individuals in their contexts. The debate on context among geographers has been synthesized in the opposition between King (1996) and Agnew (1996). While the latter insists on the importance of multi-level contextual influences on electoral choices, the former explains contextual effects by the lack of information about individuals' social characteristics. However, strong evidence on the importance of the context has been accumulated over the years. In particular, the existence of neighbourhood effects has been identified in various contexts in the literature of electoral geography. Most demonstrations of neighbourhood effects have highlighted that "people are more likely to vote with 
their class nationally if they live in a place where that class is politically dominant locally" (Johnston, 1990, p.125). However, the processes behind the neighbourhood effect and their relevant scales are still subject to debate (for a full discussion, see David and Van Hamme, 2011).

Among the few papers addressing the effect of the considered scale on the identified contextual effect, Johnston et al. (2005) studied the contextual effect measured at different scales on voting choices in the British context. We partly replicate their strategy in our concentric approach to assess the impact of various scales on the identification of contextual effects for extreme right voting and ATII.

This paper differs from previous work in two respects. First, we consider two alternative methods to assess the impact of scale in the contextual analysis of extreme right voting and ATII. The concentric approach is similar to the one applied by Johnston et al. (2005). Each contextual variable is defined as the average value of the indicator in different concentric circles around the respondent's home. The polarized approach defines a priori relevant areas in which individuals are embedded: the proximity pool, the living pool, and the employment or labour pool.

We show that the significance and the estimated effect of contextual factors change when measured at different scales. The most significant impact is to be found at the intermediate scale (municipality or 5 to $15 \mathrm{~km}$ from home) under both methods. However, when using the polarized approach, the impact of unemployment on both dependent variables is the most significant at the scale of the employment pool. These findings are interesting per se but more importantly call for a theoretical reflection on why this intermediate scale shows the strongest impact of contextual factors.

The paper is organized as follows. After a brief review of the literature on the individual and contextual factors explaining extreme right voting (Section II), the question of scale is introduced, with a focus on the extreme right (Section III). On this theoretical basis, two different methods to test the impact of contextual factors on extreme right voting and ATII at different scales are proposed (Section IV). The results of this approach are presented and analysed in Section V before a concluding discussion in Section VI.

\section{THEORETICAL FRAMEWORK: INDIVIDUAL AND CONTEXTUAL EXPLANATIONS OF THE EXTREME RIGHT VOTE AND OF ATTITUDES TOWARDS IMMIGRANTS AND IMMIGRATION (ATII)}

This paper addresses the issue of scale in contextual studies of (1) extreme right voting and of (2) attitudes towards immigrants and immigration (ATII). Theories and empirical analyses increasingly focus on contextual explanations in addition 
to the individual characteristics associated with extreme right voting and hostility toward migrants (Norris, 2005; Mudde, 2007).

At the individual level, research has shown that unemployment, low income, a lower social class, and lower levels of education appear to increase the probability to vote for the extreme right (Givens, 2002; Schuller, 2016). Yet, several publications have shown that the support for the far right goes beyond the lower class (Lubbers et al., 2000).

In addition to the individual characteristics of the voters, political scientists have also paid growing attention to the context in which the voter operates. The underlying hypothesis is that, in some contexts, voters will be more inclined to support the extreme right. Some scholars have tested the influence of contextual factors at the aggregate level (Kestilä and Söderlund, 2007; Coffe et al., 2007; Bowyer, 2008). Others have combined individual and contextual variables to provide more robust results (see, for example, Lubbers et al., 2002; Lubbers and Scheepers, 2000; Rink et al., 2009; Arzheimer, 2009). ${ }^{1}$ The most significant contextual factors are the economic context and proportion of immigrants.

The rationale of economic factors is found in Betz's modernization thesis (Betz, 1994). During recessions, competition for jobs and welfare benefits becomes more intense, and immigrants are therefore perceived as direct competitors. Under these circumstances, voters might opt for extreme right parties with restrictive views on immigration (Anderson, 1996). The presence of immigrants or the rapid rise in the number of migrants in the country constitutes the second contextual factor often studied (Golder, 2003). Some have also tried to combine these two contextual factors. Dulmer and Klein (2005) showed that the presence of immigrants might have different impacts according to the voters' level of qualification and level of unemployment. Immigrants are perceived as a threat only in a bad economic context and among the most fragile populations.

Parallel to studies of extreme right voting, another body of literature has developed since the 1950 on attitudes towards immigrants and immigration (ATII). Although the authors are often different in the two subfields, they have a great deal in common. For ATII, explanations combine individual and contextual elements, and the explanatory variables are similar. At the individual level, the most significant variables to explain negative attitudes towards immigrants and immigration are education (Quillian, 1995) and economic status (Semyonov et al., 2006). At the contextual level, the most significant variables are the size of the minority group, but only if its presence is visible and perceived (Schneider, 2008), and the state of the economy (Lahav, 2004). For ATII, the most robust findings come from studies combining individual and contextual explanations (Scheepers et al., 2002).

\footnotetext{
${ }^{1}$ For arguments on limits of contextual studies that do not take control for voters' individual characteristics, see Arzheimer and Carter's critique (2009) of Kestilä and Söderlund (2007).
} 
The theories mobilized to explain ATII are slightly different from the ones used in the study of extreme right voting. Blumer's group threat theory (Blumer, 1958) provides the central theoretical roots for this perspective. The basic principle is that the majority will feel threatened by the sudden arrival of an out-group. The threat here is economic in nature, but it can also be cultural or political (Semyonov et al., 2004). A concurrent theory has developed following the seminal work of Allport (1954) and his intergroup contact theory. Unlike group threat theory, the presence of immigrants could have a positive impact on ATII because, in ethnically diverse areas, inter-ethnic relations will emerge and thus reduce hostility between groups.

Overall, the two related fields of research share the same kinds of explanations. At the individual level, extreme right voting and negative ATII are expected to be more frequent among citizens who face a difficult economic situation and are less educated. At the contextual level, the driving factors are bad economic conditions and the presence of a significant group of migrants.

Another element the two subfields have in common is that various studies show different and sometimes contradictory results regarding the impact of these contextual factors. With regard to the influence of the economic conditions, there are divergent views in both subfields. Jackman and Volpert (1996) find a positive relation between unemployment and the attractiveness of the extreme right, while others see no relation (Chapin, 1997) or even a negative effect (Knigge, 1998). Some have found a negative effect of the economic situation on openness towards immigrants and immigration (Coenders et al., 2008). Others find no robust impact (Mayda, 2006), and others reveal an effect in only some countries (Central and Eastern Europe according to Kunovich, 2004).

Reflecting on these varying results, various authors have underlined that part of the explanation can be found in the choice of the level/scale for the contextual factors. As similar contextual factors may have different effects when considered at different scales (Arzheimer and Carter, 2009), the choice of scale must be well considered and guided beyond data availability constraints (Bowyer, 2008; Dulmer and Klein, 2005).

This paper proposes further exploration of the relevant scale for analysing the impact of contextual variables. More precisely, two aims are pursued. First, the analysis empirically confirms what has already been acknowledged in the literature (see Rydgren, 2008): the choice of scale could change the empirical effect of contextual variables. This is confirmed by testing in a coherent way and within the same general context (Belgium) different scales for the effect of the presence of immigrants and unemployment rates.

Second, not only is it argued that scales matter, but we also explore at what scale (s) the effects of the contextual factors are the strongest. On the basis of these results, a discussion can be opened with the dominant theories in the two subfields. 


\section{THE RELEVANT SCALE FOR CONTEXTUAL ANALYSIS OF THE EXTREME RIGHT}

Over the course of several studies, Johnston and his co-authors have proposed original solutions to solve the question of scale to assess the impact of the context on electoral behaviour (e.g. Johnston et al., 2005). However, they never apply their methods to the extreme right. By studying the impact of the feel-good factor on electoral behaviour, Tunstall et al. (2000) also underlined that different scales can show different impacts for the same variable. In particular, they have shown that subjective feeling and the real level of unemployment had significant impacts on voting at both the local and regional scales. Johnston et al. (2005) extended their study a step further to understand the relevant scale for contextual effects on electoral behaviour. They propose study of each contextual variable regarding its effect on individuals at different distances around the home residence. Their logic is to work in circles, considering three contextual scales: local $(250 \mathrm{~m})$, place (2000 m), and administrative regions. While socio-economic level is found to be the most significant contextual variable (whatever the considered scale), other contextual variables have different impacts according to the scale used; for example, ethnicity only plays a significant role at the very local scale $(250 \mathrm{~m})$.

This approach allows assessment of the question of scale in a progressive way, from very small to very large areas around the subject's home. It offers an advantage, since spatial processes are complex, diffuse, and difficult to capture on a single scale. In this paper, Johnston's approach is applied as a starting point to analyse extreme right voting in Belgium. However, this method also has some limits. It considers the space around a residence to be isotropic, which is obviously not the case. In particular, the geography of interactions in daily life is affected by the polarization of space. As noted by Kwan (2012), in their daily activities, individuals move from one place to another and are confronted with different contexts that could potentially affect their behaviour. However, confronted with the lack of data on the exact movements and interactions of people, we suggest taking the polarization of space into account. This polarization indeed affects the probability of individual interactions. For example, when one lives near a big city, she has a much higher probability to go to the city centre than any other place at equal distance from her home.

The choice of scale is not only a matter of methodology; it must also be linked with deeper theoretical thinking on what the relevant scale would be for the two contextual variables included in this analysis: unemployment rate and the presence of immigrants. Regarding the latter, the most natural view is that voters are affected by what they see in their everyday lives, in their immediate neighbourhood. Therefore, all things being equal, the higher the presence of immigrants at the very local scale, the more impact it should have on voters' behaviour. However, the direction of the effect is unclear. Group threat theory suggests 
that high shares of immigrants at the local level can result in more negative ATII. In contrast, intergroup contact theory assumes that diversity at the local level increases inter-group contact and thus trust between them (see Semyonov and Glikman, 2009). In addition, as both effects might occur at different scales, they could result in the so-called "halo effect" (effet de halo) from the French literature. The idea is that the extreme right performs best in areas located next to sectors where there are lots of immigrants and not within these sectors (Etchebarne, 1989; Mayer, 1987; Bowyer, 2008). At the very local level, according to the contact theory, people living in areas with lots of immigrants are familiar with their presence and are therefore less frightened by cultural differences. But at a larger level, in line with the group threat theory, negative attitudes towards immigrants might be relevant because they are not attenuated by frequent contact.

The impact of the economic context could have different effects at two different scales. First, the very local situation can have an effect on voting tendencies. Economic deprivation of neighbourhoods might increase the vote for the extreme right. This effect can be captured through socio-economic indicators such as housing, incomes, and the unemployment rate. ${ }^{2}$ However, the economic context also plays a role at another level: the employment pool. Voters are more likely to be attracted by the discourse of the extreme right depicting immigrants as "job stealers" when they have difficulties finding a job. In that respect, the relevant scale would be the employment pool, not the direct neighbourhood. This means that a very high local unemployment rate is indicative of a deprived neighbourhood but not necessarily of a lower probability of finding jobs, because labour pools function at a much larger level.

For the above-mentioned reasons, two different approaches are proposed in this paper: the concentric approach derived from Johnston et al. (2005) characterizes context as circles around homes, and the polarized approach takes into consideration the nonisotropic nature of the space.

\section{DATABASE AND METHODOLOGY}

This section presents, first, the database and variables used. Then the steps through which the optimal scales are identified to study the extreme right voting and ATII are described. Finally, we describe the estimation techniques.

\section{IV.1. Database and Variables}

To carry out this empirical analysis, data from the PartiRep Election Study (http://www.partirep.eu/) is used (See Supplementary Information 1). This voter

\footnotetext{
${ }^{2}$ However, it is inadvisable to multiply these indicators in the analysis because, as suggested by Bowyer (2008), they show high correlations between each other.
} 
survey was conducted in the two main Belgian regions - Flanders and Wallonia - for the 2009 regional elections, excluding thus the Brussels-Capital-Region. The Belgian case presents two major interests. On the one hand, a precocious rise of extreme right voting has been observed with the Vlaams Blok ${ }^{3}$ becoming a major political actor on the Flemish political scene from the 1990s onwards. On the other hand, Flanders and Wallonia show two very contrasted political, cultural, and socio-economic contexts. In particular, the extreme right parties in Wallonia, in contrast to Flanders, have been rather weak and unstable, mainly because of their lack of organization, although the economic decline of Wallonia could be considered fertile ground for their electoral success. PartiRep Election Study is a panel survey organized in three waves. Wave 1 took place a couple of weeks before the election; it collected information on individuals' characteristics, attitudes, and voting expectations; Wave 2 took place a couple of days before the election and focused on voting expectations and the use of the press during the campaign; in Wave 3, which took place a couple of days after the election, individuals were asked to report their vote. ${ }^{4}$ In Wave 1, 2,331 voters were surveyed.

Each individual has been geolocalized in order to allocate to her the appropriate contextual rates of unemployment and migrant share. The local rates of unemployment come from the 2011 census data and the local share of migrants from the National Register in 2009. ${ }^{5}$

Two dependent variables are used: the intention to vote for the extreme right and anti-immigrant attitudes (ATII) (For full description of variables, see Appendix 1).

Extreme right voting is a dummy equal to one if the individual has declared to be willing to vote for an extreme right party at any one of the three waves of the survey, even if he or she does not do it at the time of election. There are several reasons to justify using this measure and not the actual vote for extreme right parties measured in the survey's third wave (post-election). First, it increases the sample size by keeping all of the initial respondents in the analysis (the attrition rate is $21 \%$ from Wave 1 to Wave 2 and $27 \%$ from Wave 1 to Wave 3 ) and, more importantly, it allows us to integrate both voters and intentional voters of the extreme right in both Wallonia (Front National) and Flanders (Vlaams Belang). Extreme right parties are of a very different nature in Flanders and

\footnotetext{
${ }^{3}$ For juridical reasons, Vlaams Blok changed his name to Vlaams Belang in 2004.

${ }^{4} \mathrm{~A}$ more careful presentation of this database as well as a description of the variables is provided in the Appendix.

${ }^{5}$ Note that the individual characteristics (as well as the two dependant variables) are measured in 2009, while the contextual variables are observed in 2011 (for unemployment rates) or 2009 (for the presence of migrants). Since these variables are very stable over time, we believe it does not constitute an issue in this study. Using data of 2001 (unemployment) and 2006 (migrants) produce very similar results. These results are available upon request.
} 
Wallonia, but there is no theoretical reason to believe that the scale of contextual effects would also differ between the two regions. Separate analyses for the Vlaams Belang in Flanders give similar results to those presented here.

Second, even if this choice can be criticized, since an intention to vote for a party is somewhat different from an actual vote for a party, previous studies (Breen, 2000) have shown that voting for extreme parties in general and for the extreme right more specifically is under-declared and therefore underestimated by electoral surveys. In the Belgian case, previous studies using other electoral surveys have demonstrated this data problem with the extreme right (Aish-Van Vaerenbergh and Swyngedouw, 1994; Frognier, 2007). This is a general problem with surveys - what Noelle-Neumann (1984) refers to as the spiral of silence. Respondents are reluctant to admit a political choice that is socially condemned. Therefore, the underlying hypothesis is that the intention to vote for the extreme right is not at all anodyne but requires some level of adhesion. Third, the analysis of switching voters between the three waves of PartiRep Electoral Survey show that Vlaams Belang is the party that kept most of its voters from Wave 1 (pre-electoral) to Wave 3 (Walgrave et al., 2010). Fourth, when using the real vote instead of voting intention, the main message of the paper remains the same: the scale choice matters, though most results are not significant anymore.

The second dependent variable synthesizes attitudes toward immigrants and immigration (ATII). It is a measure of individual positioning on a scale combining three different statements present in the survey for which individuals are asked to pick a position on a discrete scale going from 1 to 5 (1 means that the individual fully disagrees and 5 indicates that she fully agrees with the statement presented). The statements are (i) Belgium must close the doors of asylum; (ii) It is normal that foreigners living in Belgium for more than five years can vote at the municipal election; and (iii) Immigration contributes to the wealth of our country. The Multiple Correspondence Analysis (MCA) applied to answers provided by individuals to the above statements yields an ATII index in which higher scores are associated with more negative attitudes towards immigrants and immigration. The first component captures $65 \%$ of the variance, and it appears to show a strong coherence among the answers to the three questions used to build the index. The coordinate plot on the two first dimensions and the distribution density of the index are presented in Appendix 2. The index obtained from the MCA is continuous and takes values between -2 and 2 . Higher values are associated with more negative ATII.

For the independent variables, the standard individual characteristics are combined with contextual factors. The individual control variables are similar to those used in earlier studies: age, sex, education, and socio-professional status. The model also controls for the language used at home (French or Flemish). It tries to capture the presence of Belgians having a foreign origin in the survey 
by using a dummy for Arabic, Turkish, or Berber spoken at home. ${ }^{6}$ At the contextual level, dummies are used for the region of residence (Wallonia or Flanders) and to control for the population density. Indeed, previous analyses have highlighted the urban (more specifically suburban) character of extreme right voting, notably in France (e.g. Mayer, 2002b, Buleon et al., 2003). Three levels of population densities (computed within a $4 \mathrm{~km}$ radius) are considered: urban (more than 600 inhabitants per square kilometre), intermediate (between 200 and 600), and rural (less than 200).

The purpose is to look at the influence of migrant share and economic condition at various scales. For the economic context, the level of unemployment is used. For the presence of migrants, the share of migrants from Turkey and the Maghreb is used. This choice is motivated by various studies showing that, in many European countries, though not all, the presence of migrants from Islamic countries was more a source of political reactions among citizens than the presence of other migrant groups (Savelkoul et al., 2010). This observation might likewise apply to Belgium (Meuleman and Billiet, 2003). The reality of the demographics of immigration in Belgium is much more diverse than from only Muslim-majority countries. Yet, there are several reasons that could explain why immigration for these countries has been politicized and a source of tension (Van Goidsenhoven and Pilet, 2014). First, demographically, migrants from Turkey and Morocco are, combined, the fourth largest group of foreign nationals living in Belgium. Only Dutch, French, and Italians are more present in the country, without taking into account the fact that more migrants from Morocco and Turkey have decided to demand Belgian citizenship while EU nationals have less incentives to do the same, given they are already granted most civil and social rights as EU citizens (CGKR, 2009). Second, migrants from Morocco and Turkey are less socially heterogeneous. They are more often low-skilled workers and therefore face more difficulty finding jobs. Finally, Muslim migrants raise several cultural and religious issues that other migrants (from the EU or even Congo, the former Belgian colony) do not. For these reasons, we might observe that debates about immigration in Belgium are, to a large extent, assimilated into debates about the presence of Muslim migrants and their cultural rights (e.g., the headscarf, halal food in public schools). These elements explain why we believe that the share of migrants from Turkey and Maghreb is the appropriate indicator for evaluating the effect of the number of migrants on ATII and extreme right voting. Taking all foreign nationals into consideration would blur the effect of this variable, and would lead, for example, to evaluation of whether a massive

\footnotetext{
${ }^{6}$ There are no observations of individuals speaking one of these languages and voting for an extreme right party. This leads the statistical program (Stata 12) to remove these individuals when estimating the probability to vote for an extreme right party. Nevertheless, it is important to keep this variable in the analysis; otherwise, an explanatory variable would be left out. As a robustness check, the same regressions when removing that variable were tested. Removing it tends to reinforce the findings.
} 
presence of migrants from France or the Netherlands in some areas has a significant effect on ATII or extreme right voting.

\section{IV.2. Operationalization}

Regarding the methodological issue of scale, the concentric approach is based on Johnston's idea of assessing the impact of contextual factors at different scales regarding the two dependent variables described above. It proceeds in two steps.

First, the optimal scale is explored by looking at how contextual variables (the presence of migrants and of unemployment) affect extreme right voting and ATII when measured at different scales. Each individual has been precisely geolocated at his home address. The individual's context is thus defined as the weighted average of each of our two contextual variables for all statistical districts ${ }^{7}$ whose centre is included in a circle of different radii $(500 \mathrm{~m}, 1 \mathrm{~km}, 2 \mathrm{~km}, 3 \mathrm{~km}, \ldots$, $30 \mathrm{~km}$ ) around the respondent's home. By controlling for individual characteristics, it is thus possible to assess the impact of the context at various scales. The goal is to see whether the distance at which the context is computed changes the results. Would unemployment and migration have an effect at the very local level - where the voter lives (circles of $500 \mathrm{~m}, 1 \mathrm{~km}$ )? At a medium-range level, where the voters shop, work, or study (circles of 5-10 km)? Or at a large level, where the voter goes occasionally (circles of 15-30 km)? The goal at this first stage of analysis is exploratory but also aims to show that the scale chosen makes a difference.

However, as mentioned in Section III, this method raises problems since it assumes isotropic space around the respondent's home. In a second step, the question of scales has been approached in another way that explicitly takes into account the polarization of space. Hence, the individual's context is defined according to the proximity pool, the living pool, and the employment pool. The proximity area is the district one lives in, approximated by the statistical district. The living pool corresponds to the pool in which children go to school or where one goes shopping for basic needs and is well approximated by the municipality. ${ }^{8}$ The employment pool is, in theory, the relevant scale to assess the impact of the local economic context. For each pool, contextual variables are calculated as the weighted average of each of our indicators. Table 1 summarizes the precise definitions of the three considered non-isotropic scales. These areas are used to evaluate the impact of the two contextual variables on extreme right voting and on ATII while controlling for individual voter characteristics.

\footnotetext{
${ }^{7}$ The statistical district is the smallest statistical unit in Belgium, which includes around 500 inhabitants on average

${ }^{8}$ Municipalities are big in Belgium and have been precisely created around centres. Of course, in rural areas, school or retail trade polarization might be larger than one municipality, but still the municipality represents a good proxy for the living pool that we try to capture here.
} 
Table 1

The levels used in the polarized approach

\begin{tabular}{lll}
\hline Level/Scale & \multicolumn{1}{c}{ Denomination } & \multicolumn{1}{c}{ Definition } \\
\hline Local & Proximity pool/close neighborhood & Statistical district \\
Intermediate & Living pool & Municipality \\
Large & Employment pool & All municipalities sending the most \\
& & commuters to a large employment centre \\
\hline
\end{tabular}

${ }^{\mathrm{a}}$ Employment centres are defined using two different criteria at municipal level: a ratio between the number of jobs at working place and at residential place which should be higher than 1.25 or a volume of jobs above 30000 .

In the next section, we use OLS and logit estimations (respectively, for continuous or binary dependent variables), with appropriate clustering of the standard error. A multilevel analysis has also been tested, but it did not improve results, and it was decided to keep the OLS and logit estimations only.

As will be clear with the presentation of the results, there is an implicit assumption concerning the exogeneity of individuals' location. Indeed, it is assumed that there is no endogeneity between one individual's location and his voting behaviour and ATII. In other words, it is assumed that the choice of residential location is independent from the voting behaviour or the ATII. We believe that this assumption is reasonable, as residential choices are largely driven by housing affordability and labour market opportunities (Vanneste et al., 2007). Moreover, it is possible that residence choice precedes the strong presence of migrants, provoking reactions from certain social groups. However, we cannot exclude that residential choices of people having negative attitudes toward immigrants and immigration avoid areas where migrants concentrate. This is why we explicitly address that issue with a spatial difference estimator.

\section{EMPIRICAL RESULTS}

\section{V.1. The concentric approach}

We define the optimal scale as the level at which contextual measures play the most significant role in someone's position on either the ATII index or the probability of declaring willingness to vote for an extreme right party.

To identify these optimal scales, we estimate the following relation by OLS:

$$
y_{i}=\beta_{1}{ }^{r} \operatorname{SHARE}_{i}{ }^{r}+\beta_{2} X_{i}+\beta_{3} \theta_{z}+\varepsilon_{i}
$$

where $\mathrm{y}_{\mathrm{i}}$ is the attitude toward migrants and migration of individual $i, S H A R E_{i}^{r}$ is the share of migrants or the share of unemployment measured within a radius of 
size $r(r=0.5,1,2,3, \ldots, 30 \mathrm{~km})$ around individual $i, X_{i}$ is a vector of individual characteristics (age, sex, language, socio-professional status, diploma), and $\theta_{z}$ is a set of contextual dummies (a regional dummy for Flanders, and dummies for rural, urban, or intermediate municipalities).

We use a similar specification for the voting equation where $y_{i}$ is replaced by a dummy equal to one if the individual declared to be willing to vote for an extreme right party at an interview. That equation is estimated by logit in Stata. For each specification, we run one estimation for each value of $r$.

This approach provides the first intuition of whether the considered scale affects the estimated impact of our two contextual variables. To illustrate the findings, we plot the estimated coefficients and the $95 \%$ confidence intervals for the two contextual variables computed at different radii in Figure 1 in which each dot corresponds to the estimated value of $\beta_{1}^{r}$. The complete tables are available in the Supplementary Information for $r=1,5,10,15,20 \mathrm{~km}$. The confidence intervals are obtained from the robust standard error obtained by clustering residuals at the statistical district level.

The strongest results (both in terms of estimated coefficient and significance) are found at intermediate scales, generally between 5 and 15 kilometres. Smaller radii are generally less (or not) significant in explaining extreme right voting. Also, it is interesting to note the very progressive and continuous impact of the

Figure 1

Effect of contextual variables measured at various scales on extreme right voting and ATII

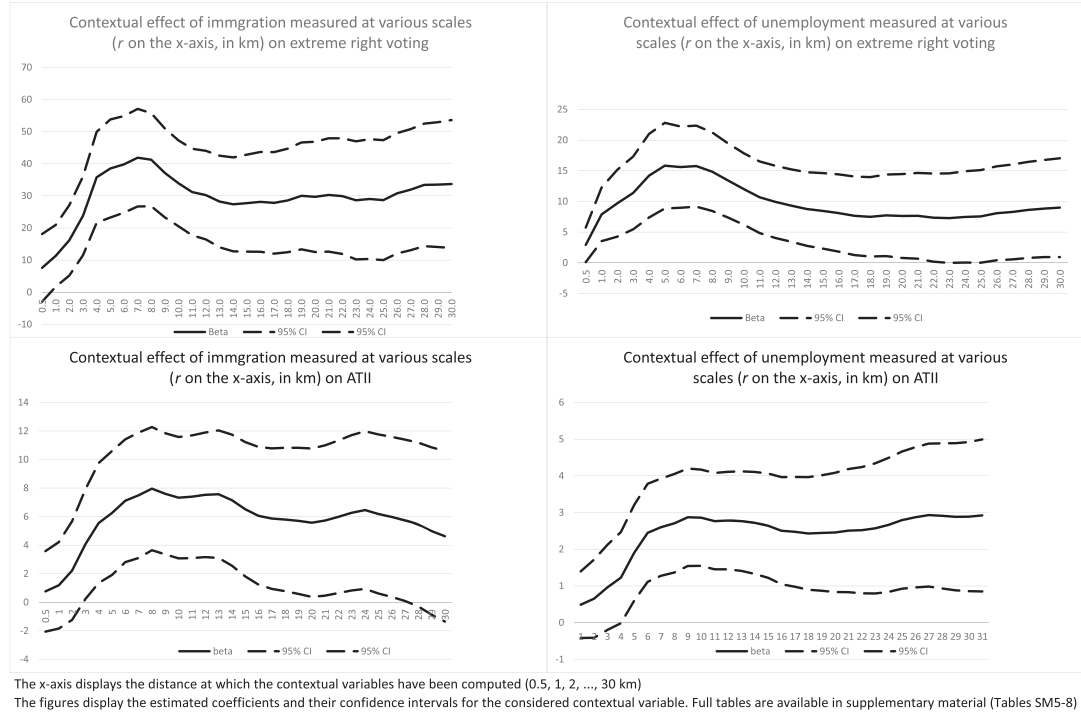


contextual variables according to scale, thus confirming the diffuse character of contextual effects, which are not easily reduced to one single scale. This result cannot only be explained by the fact that bigger radii include contextual effects of smaller ones, notably because when the radius is doubled, the contextual area is four times greater.

\section{V.2. Addressing the endogeneity issue using a spatial differencing approach}

As explained earlier, we believe that endogeneity is not an important threat in our setting for two reasons. First, it has been shown that the two main drivers for location decisions are the distance from job and housing affordability. Second, we believe that location is more persistent than attitudes or voting choices. Nevertheless, we cannot exclude the fact that people with a negative attitude toward immigrants and immigration avoid areas where migrants are concentrated. If this were the case, both the estimated coefficients and the standard error would be biased.

To address the possible endogeneity issue, we use the spatial differencing estimator described by Belotti et al. (forthcoming). The aim of that technique is to deal with the omitted variable bias generated by local specific unobservable. Instead of estimating equation 1 , we now estimate the following equation:

$$
\Delta^{d} y_{i}=\beta_{1} \Delta^{d} \operatorname{SHARE}_{i}{ }^{r}+\beta_{2} \Delta^{d} X_{i}+\beta_{3} \Delta^{d} \theta_{z}+\Delta^{d} \varepsilon_{i}
$$

where $\Delta^{\mathrm{d}}$ is the spatial difference operator. For each individual, we now take the difference between $i$ 's characteristics and the average characteristics of individuals located within the distance $d$ from $i$. As stressed by Belotti et al. (2017), "the spatial difference transformation aims to remove any source of smooth-over-space local spillovers potentially correlated with the independent variables in the model."

The estimated coefficients would now be consistent if we use the optimal distance $(d)$ for the spatial operator. Unfortunately, we have no theory or evidence suggesting the use of one distance or another. We would need to know at which distance the local spillovers affecting location choices are effective. Furthermore, there are two additional constraints in the choice of a particular distance. If we consider distances that are too small, many observations without sufficiently close neighbours will be removed from the sample. Considering distances that are too great requires a lot of computational power (and time). It is worth knowing that, when considering circles with a $1 \mathrm{~km}$ radius, $77 \%$ of individuals have at least one neighbour (in other words, we lose $23 \%$ of observations), and each individual has an average of 2.6 neighbours. These figures increase to $99.7 \%$ and 19.5 neighbours when considering $d=5$. With a $10 \mathrm{~km}$ radius, only two individuals have no neighbour, while individuals have an average of 51.5 neighbours, 
Figure 2

Spatial difference estimation at various scales ( 1 to $19 \mathrm{~km}$ ), for different distance thresholds ( $\mathrm{d}=15,10$ and $20 \mathrm{~km})$

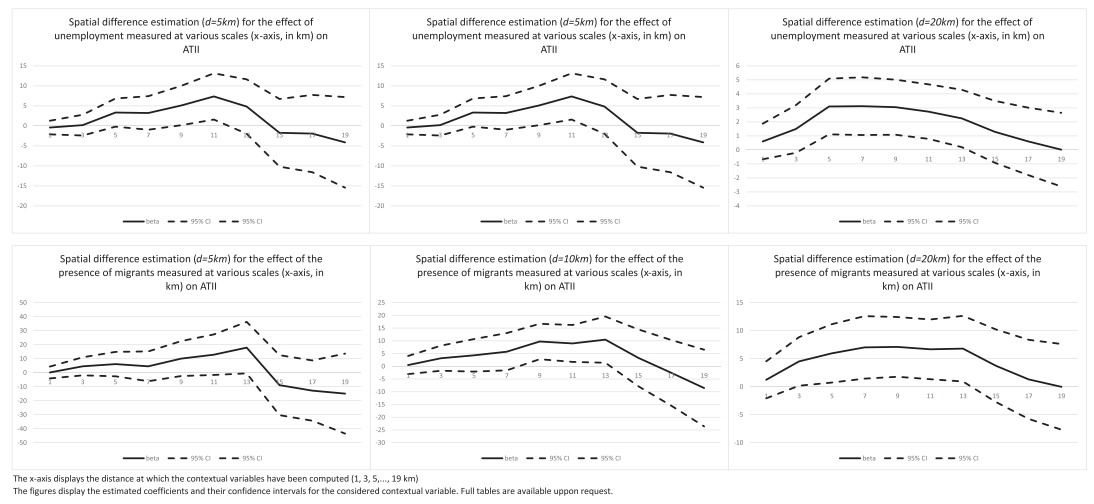

while every individual has at least one neighbour and an average of 136 individuals within a circle of $20 \mathrm{~km}$. All in all, we decided to display the results for three different distance thresholds for our spatial operator $(d): 5 \mathrm{~km}, 10 \mathrm{~km}$, and $20 \mathrm{~km}$ in Figure 2.

Figure 2 shows that taking endogeneity into consideration does not change the main message of the paper: scale matters. When looking at the spatial difference estimated coefficient with a distance threshold equal to $1 \mathrm{~km}$ (not displayed), results are never significant and very chaotic (in addition, confidence intervals are huge). When considering spatial difference estimators with a 5, 10, or $20 \mathrm{~km}$ threshold (Figure 2), intermediate scales (generally 8 to $12 \mathrm{~km}$ ) display as positive and generally have a significant impact of either the presence of migrants or the unemployment rate on political attitudes.

\section{V.3. The polarized approach}

The previous section provides insight into the appropriate scale to study the impact of the context on voting behaviour and related attitudes. It remains unsatisfactory. Space cannot be considered isotropic, and we propose an alternative approach to take into account the fact that one individual's environment must be related to her daily moves (or to the places she really sees or knows). This is done by considering three alternative scales: the statistical districts (proximity), ${ }^{9}$ the municipalities (living pool), and the employment pools. The contextual

\footnotetext{
${ }^{9} \mathrm{~A}$ statistical district is the smallest statistical unit available for Belgium. On average, it encompasses 500 inhabitants.
} 
Table 2

Summary of the contextual effect of unemployment and the presence of migrants on willingness to vote for an extreme right party

\begin{tabular}{|c|c|c|c|c|c|c|c|}
\hline & (1) & (2) & (3) & (4) & (5) & (6) & (7) \\
\hline Dependent variable & \multicolumn{7}{|c|}{$\begin{array}{l}\text { Dummy equal to } 1 \text { if individual declared to be willing to vote for } \\
\text { an extreme right party } \\
\text { Logit estimations }\end{array}$} \\
\hline \multicolumn{8}{|l|}{ Rate of unemplouyment in } \\
\hline Statistical district & $\begin{array}{l}3.412 * \\
(1.658)\end{array}$ & & & $\begin{array}{c}1.039 \\
(2.116)\end{array}$ & $\begin{array}{c}2.540 \\
(1.889)\end{array}$ & & $\begin{array}{c}0.944 \\
(2.503)\end{array}$ \\
\hline Municipality & & $\begin{array}{l}9.950^{*} \\
(3.880)\end{array}$ & & $\begin{array}{l}8.995+ \\
(4.656)\end{array}$ & & $\begin{array}{c}7.211^{* *} \\
(2.138)\end{array}$ & $\begin{array}{l}6.362^{*} \\
(3.173)\end{array}$ \\
\hline Employment pool & & & $\begin{array}{l}10.31 * * \\
(2.619)\end{array}$ & & $\begin{array}{c}9.702 * * \\
(2.517)\end{array}$ & $\begin{array}{c}8.644^{* *} \\
(2.185)\end{array}$ & $\begin{array}{c}8.615 * * \\
(2.183)\end{array}$ \\
\hline Contextual control variables & YES & YES & YES & YES & YES & YES & YES \\
\hline Individual control variables & YES & YES & YES & YES & YES & YES & YES \\
\hline Observations & 2,213 & 2,213 & 2,213 & 2,213 & 2,213 & 2,213 & 2,213 \\
\hline $\begin{array}{l}\text { Pseudo R-squared } \\
\text { Share of migrants from }\end{array}$ & 0.157 & 0.160 & 0.162 & 0.161 & 0.163 & 0.165 & 0.165 \\
\hline Maghreb and Turkey in... & & & & & & & \\
\hline Statistical district & $\begin{array}{c}7.310 \\
(5.264)\end{array}$ & & & $\begin{array}{l}-0.005 \\
(3.845)\end{array}$ & $\begin{array}{l}5.102^{*} \\
(2.534)\end{array}$ & & $\begin{array}{l}-0.205 \\
(3.947)\end{array}$ \\
\hline Municipality & & $\begin{array}{c}24.14 * * \\
(7.126)\end{array}$ & & $\begin{array}{c}24.15^{* *} \\
(8.001)\end{array}$ & & $\begin{array}{l}18.43^{* *} \\
(5.198)\end{array}$ & $\begin{array}{l}18.57^{* * *} \\
(6.539)\end{array}$ \\
\hline Employment pool & & & $\begin{array}{c}22.10^{* *} \\
(4.873)\end{array}$ & & $\begin{array}{c}21.20^{* *} \\
(4.842)\end{array}$ & $\begin{array}{l}17.68^{* *} \\
(5.005)\end{array}$ & $\begin{array}{r}17.69 * * \\
(4.990)\end{array}$ \\
\hline Contextual control variables & YES & YES & YES & YES & YES & YES & YES \\
\hline Individual control variables & YES & YES & YES & YES & YES & YES & YES \\
\hline Observations & 2,207 & 2,207 & 2,207 & 2,207 & 2,207 & 2,207 & 2,207 \\
\hline Pseudo R-squared & 0.156 & 0.162 & 0.162 & 0.162 & 0.163 & 0.166 & 0.166 \\
\hline
\end{tabular}

Robust standard errors in parentheses $* * p<0.01, * p<0.05,+p<0.1$

Coefficient for all control variables are presented in Tables SM1 and SM2 in the supplement

explanatory variables (rate of unemployment and migrant share) are now computed at each of these scales. In addition, three dummies (rural, intermediate, and urban) have been included to control for the urban character of the municipality. The additional control variables are described in the previous section, and robust standard errors are clustered at, respectively, the statistical district, the municipality, and the employment pool levels.

The results presented in Summary Tables 2 and 3 (complete tables are available in Supplementary Information 3, Tables SM.5 to SM.8) generally confirm the relevance of intermediate scales (municipalities here, $4 \mathrm{~km}$ and $8 \mathrm{~km}$ radii in the previous analysis) for both contextual variables. This suggests that the presence of migrants has a greater impact on ATII (though results here are slightly significant) or extreme right voting in the surrounding areas than within the immediate vicinity of the voter, confirming the higher impact of intermediate scale. Focusing on unemployment, the optimal scale is not the same in explaining ATII and voting behaviour. Indeed, the rate of unemployment 


\section{SCALE MATTERS IN CONTEXTUAL ANALYSIS}

Table 3

Summary of the contextual effect of unemployment and the presence of migrants on ATII

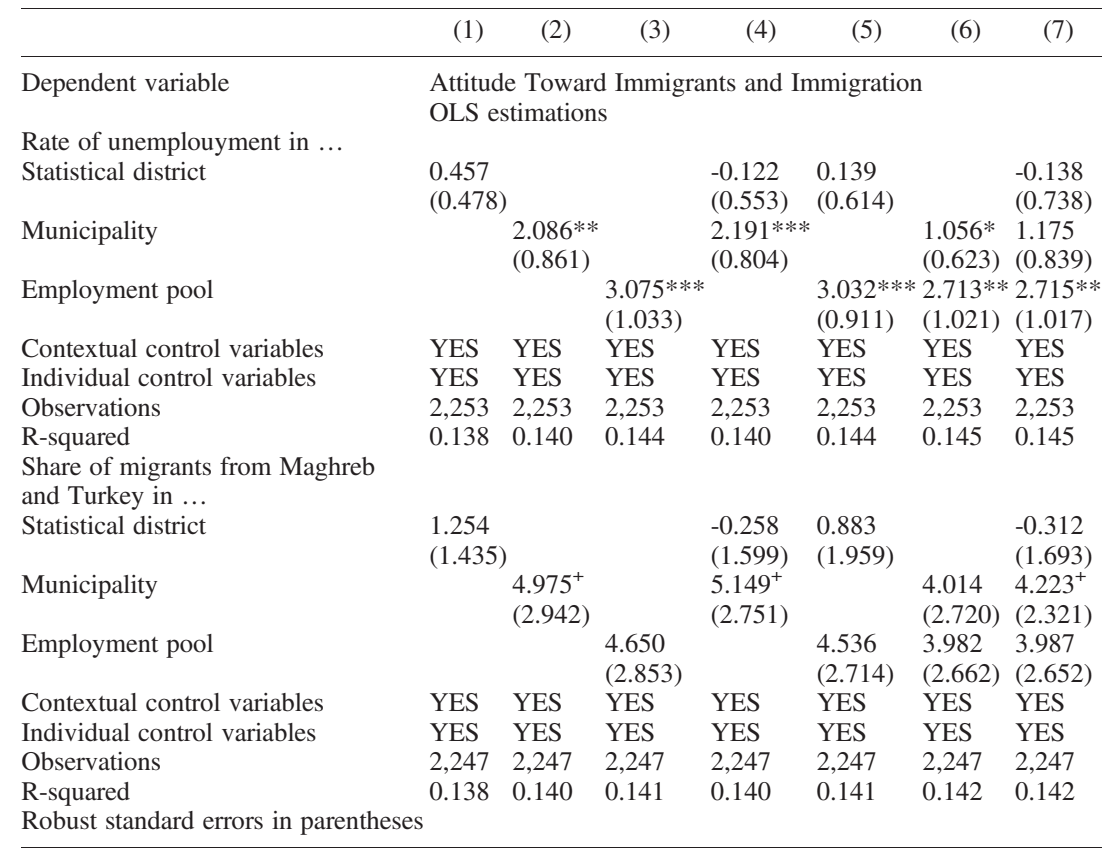

$* * \mathrm{p}<0.01, * \mathrm{p}<0.05,{ }^{+} \mathrm{p}<0.1$

Coefficient for all control variables are presented in Tables SM3 and SM4 in the supplement

seems to be mainly related to ATII in the employment pool (Tables 2 and 3), in line with the theoretical reflection about the potential impact of this variable. However, we must note that the impact is also highly significant at the municipality level.

We also test whether the coefficients presented in the three first columns of Summary Tables 2 and 3 are significantly different from each other. Generally speaking, the coefficients obtained at the statistical district scales are significantly different from those obtained at the municipal or employment pool level. In contrast, the difference is generally not significant between employment pool and municipality. Converting the estimated coefficient into marginal probabilities, we find that, according to column 2 s 1 -Table 2 , for a reference individual ${ }^{10}$ (male, 48 years old, living in an urban municipality, located in Flanders,

\footnotetext{
${ }^{10}$ The reference individual considered for this quantification has the following characteristics: Male, 48 years old, living in an urban municipality located in Flanders, speaking Flemish, at collar lower level with a diploma from secondary school. We assume that the contextual unemployment (whatever the considered scale) is at $8 \%$.
} 
speaking Flemish, collar lower level with a diploma from secondary school and a contextual unemployment of $7 \%$ in his municipality of residence), the probability to be willing to vote for an extreme right party is $20 \%$. Increasing the unemployment rate by 10 percentage points would increase the marginal probability for that individual to be willing to vote for an extreme right party by $1.65 \%$. The impact of increasing the presence of migrants in the municipality by 10 percentage points would increase the marginal probability that an individual is willing to vote for an extreme right party by 3.3 points (not significant) within the statistical district and by about $10.1 \%$ if it takes place at the level of the municipality or the employment pool.

Finally, before entering a deeper discussion on our variables of interests, we propose here a short discussion on the impact of the different control variable on extreme right voting and ATII.

Concerning individual characteristics, several interesting results can be drawn from Tables A.5 to A.8. First, age has a negative impact on the intention to vote for the extreme right but not on ATII, while it is worth noting that being a student has a very negative impact on both dependent variables. This suggests that people of intermediate ages are most likely to vote for the extreme right, though they do not necessarily show more negative attitudes towards migrants, which is in line with earlier studies (Rydgren, 2008). Second, in contrast to most studies, being a man does not significantly impact the intention to vote for the extreme right while it has an impact on ATII (Lubbers et al., 2002). Third, when the diploma level is taken into account, social class does not impact our dependent variables, while, in line with other studies on extreme right and ATII, the higher the diploma, the less probable the vote for extreme right and ATII (Lubbers \& Scheepers, 2000).

Concerning contextual effects, both the region of residence and the urban/rural character of the municipality have been introduced in the regressions. The impact of region is very clear: residence in Flanders strongly affects one's intention to vote for the extreme right. This contrast between both parts of Belgium has already been widely commented on in the literature (see, for example, Van Hamme, 2008). There is agreement on the importance of the electoral offer as a major driver to explain such a difference, and, in particular, the low capacity of the French-speaking extreme right voters' movement to organize and to find a place in the partisan system. Indeed, regarding ATII, we do not find a significant difference between Flanders and Wallonia, suggesting again that the electoral offer is the main driver here. Finally, the contrast between urban and rural contexts to explain the extreme right vote and ATII must be underlined. While no significant difference is found to explain ATII, the intention to vote for the extreme right is significantly lower in rural contexts. In other words, if the rural context seems to be an obstacle for extreme right voting, it is not the case for anti-immigrant attitudes. 


\section{DISCUSSION}

In recent works, various scholars have underlined the fact that studies can produce different results for the same research questions simply because of the data used. As stated by Mudde and Schedler, "the numbers we use, the world we see." 11 To synthesize the main message of our paper, we can paraphrase Mudde and Schedler, "the scale we use, the world we see." Going through the literature on the impact of contextual factors - mainly immigration and unemployment on extreme right performance and on attitudes towards immigrants and immigration, reveals that there was no consensus on their actual effect. Various studies showed different and sometimes contradictory results. One explanation provided in the literature (HIPP, 2007) is that the scale used to measure contextual effects may explain some of these differences. Thus, the studies focusing on contextual effects must reflect on the scale chosen, because choosing the wrong scale could lead to the wrong conclusions.

In this paper, a systematic test of how the scale chosen can affect the impact of two contextual variables (unemployment and the share of migrants) on extreme right voting and ATII is proposed using two approaches. First, context is defined via concentric circles of various sizes around a home, from small to large radii. This concentric approach enables us to test how the impact of contextual variables varies with scale. This is useful, considering that spatial processes are diffuse and complex. Its weakness is that it considers the probability of contextual influences to be equally distributed around an individual's place of residence, while daily activities are affected by the polarization of space. Using the polarized approach, we tested the impact of contextual variables, taking into account the polarization of space at three different levels: the proximity pool (close neighbourhood), the living pool (the area where children go to school or where individuals go shopping), and the employment pool (the functional economic area around city centres). Lacking data on actual daily activities of individuals, the pools provide possible ways to capture potential interactions at different scales.

With both methods, the results highlight the relevance of the intermediary scale (5-15 $\mathrm{km}$ radius around the home or the living pool). This result contradicts the usual expectations which often implicitly assume that the lower the scale, the better contextual effects will be captured. To go a step further, we propose a reflection on why the intermediary scale appears to be the most appropriate, taking into account the theoretical background developed above.

Considering the impact of the presence of migrants, these results are in line with theoretical expectations. At the very local scale, the presence of immigrants

\footnotetext{
${ }^{11}$ See the workshop they organized at the 2008 ECPR Joint Sessions of Workshops in Rennes (France). A special issue of Political Research Quarterly (2010 vol. $\left.63 \mathrm{n}^{\circ} 2\right)$ was dedicated to the issue.
} 
does not seem to have an effect on extreme right voting and ATII. This result can be interpreted using the intergroup contact theory by Allport (1954) and the idea that frequent contact with migrants (associated with less residential segregation) reduces negative ATII. One cannot, however, exclude that the most hostile individuals avoid areas where migrants locate. Considering larger scales, the pertinence of the presence of immigrants to explain an individual's behaviour seems to fade. We also observe the significant impact of the presence of immigrants on both extreme right voting and ATII at intermediate scales. This may reflect what Mayer (1987) identified as the "halo effect," underlying the observation that extreme right parties were performing better in areas next to districts with lots of migrants than in districts where migrants actually lived. This is because intermediate distance might be related to interactions which are regular but not frequent enough to counter distrust and improve inter-cultural comprehension.

Considering the effect of unemployment, both Blumer's group threat theory (Blumer, 1958) and Betz's idea of the losers of modernization (Betz and Immerfall, 1998) imply that larger levels would be more relevant. Indeed, the employment pool is precisely where the competition for jobs takes place, where citizens look for job opportunities. Indeed, in our polarized approach, the most significant impact is found at the employment pool. However, the results of this article seem to show a much more complex reality. Indeed, if one considers the distance around a home, what is observed is a more significant impact on the intermediate rather than larger scales. A possible interpretation is that, at larger scales, considering the radii around a home might result in considering that the individual's interactions are exactly the same in all directions, while, in the real world, an individual's social interactions are biased toward, for example, an employment centre. Thus, the polarization of space should be taken into account when assessing the effect of contextual variables.

One should also pay attention to the fact that our models explain around 15\% of the variance. Such low $\mathrm{R}^{2}$ are usual when modelling political attitudes and electoral choices, notably because they are mediated by socialization processes which include all ranges of influences encountered by individuals. In addition, political attitudes are also deeply impacted by the socio-economic and political circumstances of the elections, resulting in some electoral volatility.

One should keep in mind that our results have been produced in the specific case of Belgium, a country characterized by a very high population density and very dense network of small and medium cities, particularly in Flanders. It is possible that this might influence the results because the impact of distance could be dependent on spatial structures. This is particularly true for the concentric approach. In contrast, the approach based on the functional divisions of space (proximity, living, and employment pools) is probably less impacted by the specific spatial structures of Belgium because, for example, employment pools in 
low-density contexts simply cover much larger areas. That being said, we have no reason to believe that it affects our main message; i.e. scale matters when looking for the impact of context on individuals. However, the optimal scale found in our analyses - the intermediate scale - could be affected by the high densities of Belgium. But even here, one of the interesting findings is the lower impact found at the small scale, which is rather counterintuitive. Hence, while the success of extreme right parties across Europe does not show any sign of decline, any assessment of the impact the context and individual's political attitudes should at least pay attention to the importance of the scale used.

Finally, the above discussion rests on the implicit assumption that our results are not affected by endogeneity. As discussed previously, we believe that endogeneity is not an issue in this case. Voting choice does not drive residential location, while it is likely that the presence of migrants affects location decisions, but in the direct vicinity only. As a consequence, we believe that, if there is any endogeneity, it affects our results only at very small scales (at the $500 \mathrm{~m}$ radius or at the statistical district level). Unfortunately, we do not have the possibility to address that issue directly (we do not have variables likely to be used as instruments in our database). Furthermore, even if there were some endogeneity, it would not change the main message of our paper. If one considers our estimations to assess the partial correlations between the considered variables (assuming there is no causal relation), we still find that "the scale we use, the world we see," in the sense that the measured correlations depend on the considered scales.

\section{REFERENCES}

Agnew J.A. (1996) Mapping politics: how context counts in electoral geography, Political Geography $15,129-146$.

Aish-Van Vaerenbergh A-M. and Swyngedouw, M. (1994) Stabilité et instabilité du vote en Wallonie: désalignement et réalignement des électeurs, in Frognier, A-P and Aish-Van Vaerenbergh A-M. (Eds.) Elections. La fêlure. pp.61-76, De Boeck, Brussels.

Allport G. (1954) The Nature of Prejudice. Doubleday Anchor, New York.

Anderson C.J. (1996) Economics, politics, and foreigners: populist party support in Denmark and Norway, Electoral Studies 15 (4), 497-511.

Arzheimer K. and Carter E. (2009) How (not) to operationalize subnational political opportunity structures: a critique of Kestilä and Söderlund's study of regional elections, European Journal of Political Research 48 (3), 335-358.

Arzheimer K. (2009) Contextual Factors and the Extreme Right Vote in Western Europe, 1980-2002, American Journal of Political Science 53 (2), 259-275.

Belotti, F., Di Porto E. and Santoni, G. (forthcoming), Spatial Differencing: Estimation and Inference, CESifo Economic Studies.

Belotti, F., Di Porto E. and Santoni, G. (2016), The effect of local taxes on firm performance: evidence from geo referenced data, Working Paper CEPII.

Berelson B. R., Lazarsfeld P. F. and McPhee W. N. (1954) Voting: a study of opinion formation in a presidential campaign, Chicago University Press, Chicago.

Betz H-G. (1994) Radical Right-Wing Populism in Western Europe. Macmillan, Basingstoke. 
Betz H-G. and Immerfall S. (Eds.) (1998) The new politics of the right: Neo-populist parties and movements in established democracies. Macmillan, Basingstoke.

Braconnier C. (2010) Une autre sociologie du vote, Les électeurs dans leurs contextes: bilan critique et perspectives. Université de Cergy-Pontoise/LEJEP, Lextenso-éditions.

Breen R. (2000) Why is support for extreme parties underestimated by surveys? A latent class analysis, British Journal of Political Science 30 (2), 375-382.

Blumer H. (1958). Race prejudice as a sense of group position, Pacific Sociological Review 1, 3-7.

Bowyer B. (2008), Local context and extreme right support in England: The British National Party in the 2002 and 2003 local elections, Electoral Studies 27 (4), 611-620.

Buleon P., Fourquet J. and Ravenel L. (2003) Vote et gradient d'urbanité: les nouveaux territoires des élections présidentielles de 2002, Espaces, Population, Société 3, 469-482.

Ceobanu A.M. and Escandell X. (2010) Comparative Analyses of Public Attitudes Toward Immigrants and Immigration Using Multinational Survey Data: A Review of Theories and Research, Annual Review of Sociology 36, 309-328.

CGKR (Centrum voor Gelijkheid van Kansen en voor Racismebestrijding) (2009) Migraties en migrantenpopulaties in België. Statistisch en demografisch verslag 2008, Centrum voor Gelijkheid van Kansen en voor Racismebestrijding, Brussels.

Chapin W.D. (1997) Explaining the electoral success of the new right: the German case. West European Politics 20 (2), 53-73.

Coenders M., Lubbers M. and Scheepers P. (2008) Support for repatriation policies of migrants: comparisons across and explanations for European countries, International Journal of Comparative Sociology 49 (2-3), 175-194

Coffe H., Heyndels B. and Vermeir J. (2007) Fertile grounds for extreme right-wing parties: Explaining the Vlaams Blok's electoral success, Electoral Studies 26 (1), 144-155.

David Q. and Van Hamme G. (2011) Pillars and Electoral Behavior in Belgium: The Neighborhood Effect Revisited, Political Geography 30, 250-262.

Dulmer H. and Klein M. (2005) Extreme right-wing voting in Germany in a multilevel perspective: a rejoinder to Lubbers and Scheepers, European Journal of Political Research 44 (2), 243-263

Etchebarne S. (1989) Le FN dans le Nord ou les logiques d'une implantation électorale, in Mayer N. and Perrineau P. (Eds.), Le Front national à découvert, pp. 284-306, Presses de la Fondation nationale de Sciences politiques, Paris.

Franklin M.N. (2002) The future of election studies, in Franklin M.N. and Wlezien C. (Eds.) The Future of Election studies. Mass. Pergamon, Boston.

Frognier A-P. (2007) Les déterminants du vote (1999-2003), in Frognier A-P., De Winter L. and Baudewijns P. (Eds.) Elections: le reflux ?, pp. 33-50, De Boeck, Brussels.

Givens T.E. (2002) The role of socioeconomic variables in the success of radical right parties, in Schain M., Zolberg A.R. and Hossay P. (Eds.) Shadows over Europe: the Development and Impact of the Extreme Right in Western Europe, pp. 137-158, Palgrave MacMillan, New York,.

Golder M. (2003) Explaining variation in the success of extreme right wing parties in Western Europe, Comparative Political Studies 36 (4), 432-466.

Hipp J.R. (2007) Block, Tract, and Levels of Aggregation: Neighbourhood Structure and Crime and Disorder as a Case in Point, American Sociological Review 72, 659-680.

Johnston R.J. (1990). Lipset and Rokkan revisited: electoral cleavages, electoral geography, and electoral strategy in Great Britain. In Johnston R.J., Shelley, F. and Taylor P.J. (Eds.) Developments in electoral geography. London: Routledge.

Johnston R.J., Propper C., Burgess S., Sarker R., Bolster A. and Jones K. (2005) Spatial scale and the neighbourhood effect: Multinomial models of voting at two recent British general elections, British Journal of Political Science 35 (3), 487-514.

Jackman R.W. and Volpert K. (1996) Conditions favouring parties of the extreme right in Western Europe, British Journal of Political Science 26 (4), 501-521. 


\section{SCALE MATTERS IN CONTEXTUAL ANALYSIS}

Kestilä E. and Söderlund P. (2007) Subnational political opportunity structures and the success of the radical right: Evidence from the March 2004 regional elections in France, European Journal of Political Research 26 (4), 773-796.

King G. (1996) Why context should not count?, Political Geography 15, 159-164.

Knigge P. (1998) The ecological correlates of right-wing extremism in Western Europe, European Journal of Political Science 34 (2), 249-279.

Kunovich R.M. (2004) Social structural position and prejudice: an exploration of cross-national differences in regression slopes, Social Science Research 33, 20-44

Kwan M-P. (2012) The uncertain geographic context problem. Annals of the Association of American Geographers, 102 (5), 958-968

Lahav G. (2004) Immigration and Politics in the New Europe: Reinventing Borders, Cambridge University Press, Cambridge

Lubbers M., Gijsberts M. and Scheepers P. (2002) Extreme Right-Wing Voting in Western-Europe, European Journal of Political Research 41 (3), 345-378.

Lubbers M. and Scheepers P. (2000) Individual and contextual characteristics of the German extreme right-wing vote in the 1990's: A test of complementary theories, European Journal of Political Research 38 (1), 63-94.

Lubbers M., Scheepers P. and Billiet J. (2000) Multilevel modeling of Vlaams blok voting: Individual and contextual characteristics of the Vlaams blok vote, Acta Politica 35 (4), 363-398.

Mayda A.M. (2006) Who is against immigration? A cross-country investigation of individual attitudes toward immigrants, Review of Economics and Statistics 88 (3), 510-530.

Mayer N. (1987) De Passy à Barbès. Deux visages du vote Le Pen à Paris, Revue française de science politique 37 (6), 891-906.

Mayer N. (2002a) Ces Français qui votent Le Pen, Flammarion, Paris.

Mayer N. (2002b) Les hauts et les bas du vote Le Pen 2002, Revue française de science politique 52 (5-6), 505-520.

Meuleman B. and Billiet J. (2003) De houding van Vlamingen tegenover 'oude' en 'nieuwe' migranten: diffuus of specifiek?, Administratie Planning en Statistiek. Ministerie van de Vlaamse Gemeenschap, pp. 137-176, Brussels, Belgium.

Mudde C. (2007) Populist Radical Right Parties in Europe, Cambridge University Press, Cambridge.

Noelle-Neumann E. (1984) The Spiral of Silence. Public Opinion-Our Social Skin, The University of Chicago Press, Chicago.

Norris P. (2005) Radical Right: Voters and Parties in the Regulated Market. Cambridge University Press, Cambridge.

Quillian L. (1995) Prejudice as a response to perceived threat: population composition and antiimmigrant and racial prejudice in Europe, American Sociological Review 60 (4), 586-611.

Rink N., Phalet K. and Swyngedouw (2009) The Effects of Immigrant Population Size, unemployment, and Individual Characteristics on Voting for the Vlaams Blok in Flanders 1991-1999, European Sociological Review 25 (4), 411-424.

Rydgren J. (2008) Immigration sceptics, xenophobes or racists? Radical right-wing voting in six West European countries. European Journal of Political Research 47 (6), 737-765.

Savelkoul M., Scheepers P., Tolsma J. and Hagendoorn L. (2010) Anti-Muslim Attitudes in The Netherlands: Tests of Contradictory Hypotheses Derived from Ethnic Competition Theory and Intergroup Contact Theory, European Sociological Review, published online first https://doi.org/ $10.1093 /$ esr/jcq03.

Schuller S. (2016) The Effects of 9/11 on Attitudes toward Immigration and the Moderating Role of Education; KYKLOS, Vol. 69(4).

Scheepers P., Gijsberts M. and Coenders M. (2002) Ethnic exclusionism in European countries: public opposition to civil rights for legal migrants as a response to perceived group threat, European Sociological Review 18 (1), 17-34 


\section{QUENTIN DAVID/JEAN-BENOIT PILET/GILLES VAN HAMME}

Schneider S.L. (2008) Anti-immigrant attitudes in Europe: outgroup size and perceived ethnic threat. European Sociological Review 24 (1), 53-67.

Semyonov M., Raijman R., Yom-Tov A. and Schmidt P. (2004) Population Size, Perceived Threat, and Exclusion: a Multiple-Indicators Analysis of Attitudes toward Foreigners in Germany, Social Science Research 33, 681-701.

Semyonov M., Raijman R. and Gorodzeisky A. (2006) The rise of antiforeigner sentiment in European societies, 1988-2000, American Sociological Review 71, 426-449.

Semyonov M. and Glikman L. (2009) Ethnic Residential Segregation, Social Contacts, and Anti-Minority Attitudes in European Societies, European Sociological Review 25 (6), 693-708.

Tunstall H., Rossiter D.J., Pattie C.J., MacAllister I., Johnston R.J., and Dorling D.F.L. (2000) Geographical scale, the Feel-good factor, and voting at the 1997 general election in England and Wales, Transactions of the Institute of British Geographers 25 (1), 51-64.

Van Goidsenhoven G., and Pilet J-B. (2014). The politicization of immigration in Belgium. in Van Der Brug W., D'Amato G. and Ruedin D., The politicization of immigration in Europe, Routledge, London (forthcoming).

Van Hamme G. (2008) La géographie de l'extrême-droite peut-elle s'expliquer par l' " ethnocentrisme » des territoires ? Une analyse multiscalaire en Europe occidentale, Espace, Populations, Sociétés 2008 (3), 441-452.

Vanneste D., Thomas I. and Goosens L. (2007) Le logement en Belgique, Monographie de l'enquête socio-économique de 2001, SPF Economie, Brussels, Belgium.

Walgrave S., Lefevere J. and Hooghe M. (2010) Volatiel of wispelturig? Hoeveel en welke kiezers veranderden van stemvoorkeur tijdens de campagne?, in Deschouwer, K., Delwit P., Hooghe M. and Walgrave S. (Eds.) De stemmen van het volk: een analyse van het kiesgedrag in Vlaanderen en Wallonië op 7 juni 2009, pp. 29-50, VUB Press, Brussels. 
SCALE MATTERS IN CONTEXTUAL ANALYSIS

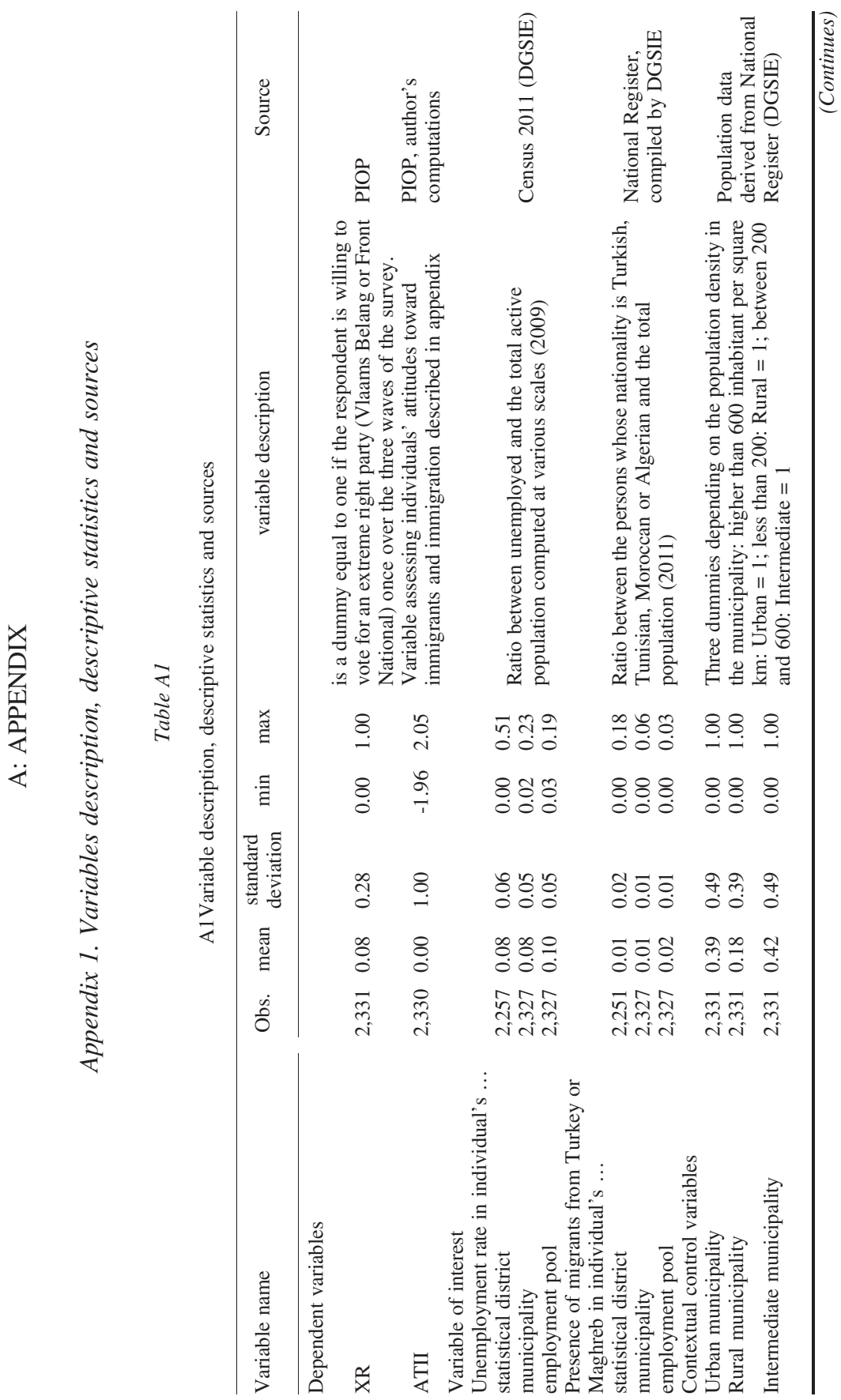


QUENTIN DAVID/JEAN-BENOIT PILET/GILLES VAN HAMME

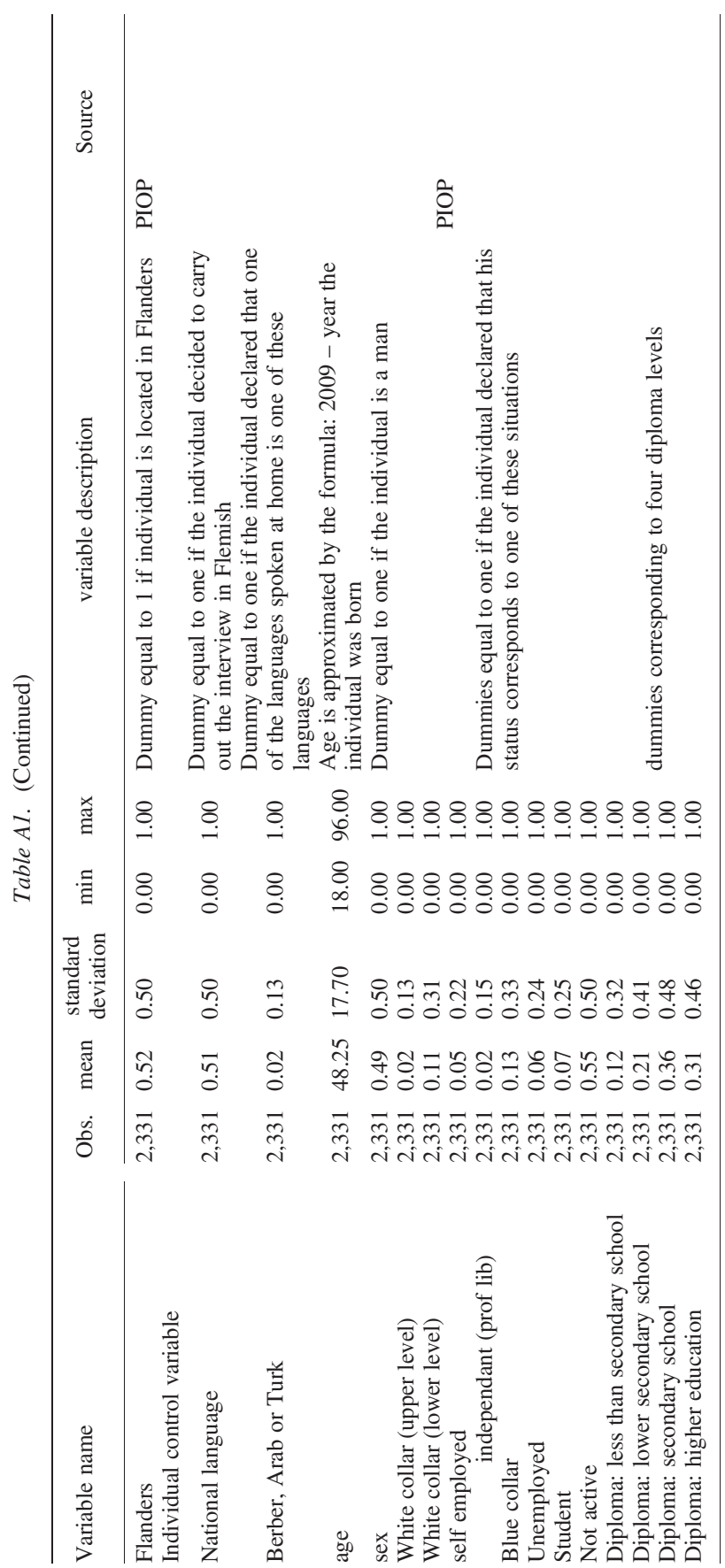




\section{Appendix 2. ATII index}

The index is obtained from a Multiple Correspondence Analysis performed in Stata on the answers at three questions presented below. The index has no units. It is a continuous measure between -2 and 2 . Higher values are associated to more negative attitudes toward immigrants and immigration. The complete tables can be provided upon request.

Figure A.2.1

Coordinate plot of the Multiple Correspondence Analysis for the construction of the Attitude Toward Immigrants and Immigration (ATII). [Colour figure can be viewed at wileyonlinelibrary.com]

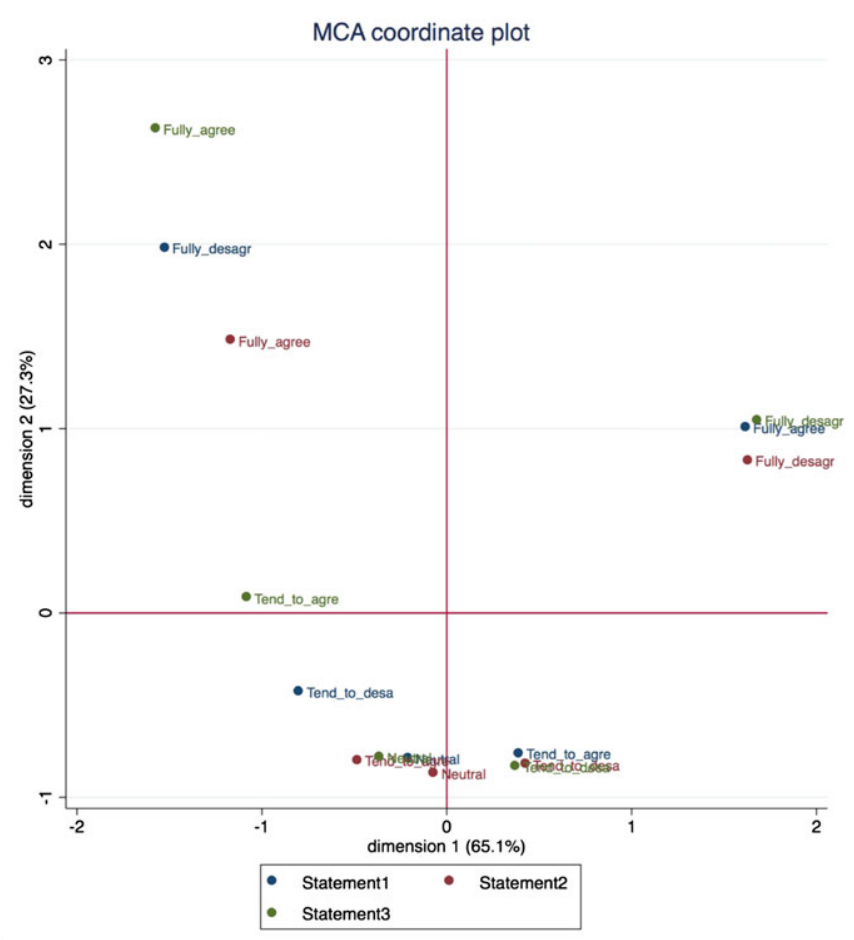

coordinates in standard normalization

Statement 1: Belgium must close the doors of asylum

Statement 2: It is normal that foreigners living in Belgium for more than 5 years can vote at the municipal elections

Statements 3: Immigration contributes to the wealth of our country

The variance captured by each dimension appears in parenthesis 


\section{QUENTIN DAVID/JEAN-BENOIT PILET/GILLES VAN HAMME}

Figure A.2.2

Distribution density of the ATII index obtained using the mca command in Stata. [Colour figure can be viewed at wileyonlinelibrary.com]

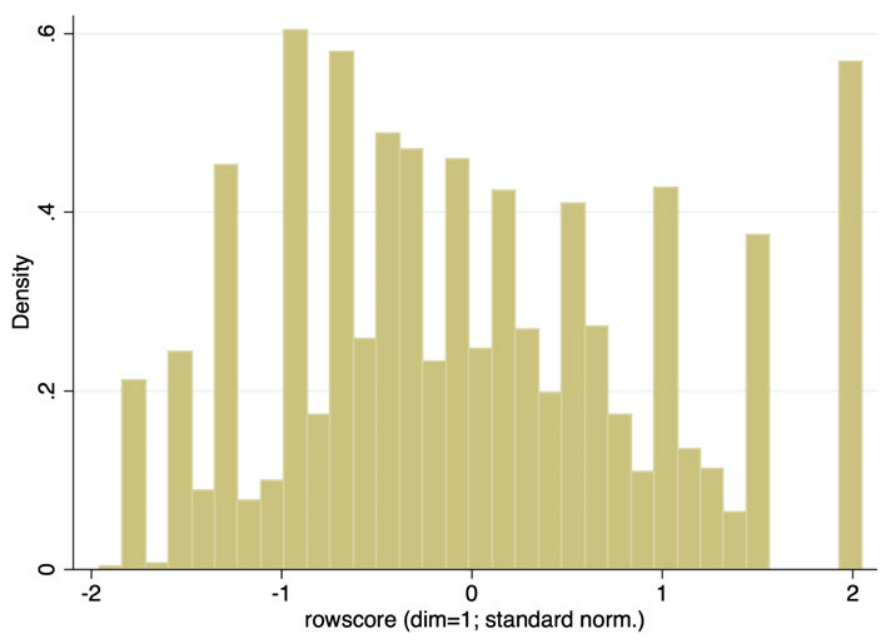

SUMMARY

A large body of literature has explored the rise of extreme right parties since the 1980s in Europe. A number of studies have assessed whether the context, particularly the level of unemployment and immigration, impacts support for the extreme right and found contradictory results. We argue in this paper that these contradictions might simply result from differences in the scale used to assess the context. We systematically test the impact of immigration and unemployment, measured at various scales, on extreme right voting and attitudes towards immigrants and immigration, using two alternative approaches with data for Belgium. In the concentric approach, we measure the unemployment and the presence of migrants within various radii around each respondent's residence. In the polarized approach, we consider the actual polarization of space, using the very local scale (statistical district), the living pool (municipality), and the employment pool. We show that the scale choice changes the results and that the most significant impacts are generally found at intermediary scales. 